\section{Quantifying Freeze Tolerance of Hybrid Bermudagrasses Adapted for Golf Course Putting Greens}

\author{
Lakshmy Gopinath \\ Department of Horticulture and Landscape Architecture, Oklahoma State \\ University, Stillwater, OK 74078
}

Justin Quetone Moss

Department of Horticulture and Landscape Architecture, Oklahoma State University, Stillwater, OK 74078

\section{Yanqi Wu \\ Department of Plant and Soil Science, Oklahoma State University, Stillwater, OK 74078}

Additional index words. artificial freezing, controlled environment, Cynodon dactylon, Cynodon transvaalensis, lethal temperature, winter

\begin{abstract}
The susceptibility of warm-season turfgrasses such as bermudagrass (Cynodon spp.) to winter injury in the transition zone is a major concern. Therefore, the objective of the study was to evaluate five golf course putting green-type experimental genotypes (OKC6318, OKC0805, OKC1609, OKC0920, and OKC3920) and three commercially available bermudagrasses ('Champion Dwarf', 'TifEagle', and 'Tahoma 31') for freeze tolerance by subjecting them to 11 freezing temperatures $\left(-4\right.$ to $\left.-14^{\circ} \mathrm{C}\right)$ under controlled environment conditions. The experiment was conducted in batches, with four genotypes per batch, and each batch was replicated in time. The mean lethal temperature to kill $50 \%$ of the population $\left(\mathbf{L T}_{\mathbf{5 0}}\right)$ for each genotype was determined. There were significant differences in $\mathbf{L T}_{50}$ values among the bermudagrass genotypes. 'Champion Dwarf' had an $\mathbf{L T}_{\mathbf{5 0}}$ value ranging from -5.2 to $-5.9^{\circ} \mathrm{C}$ across all three batches. The experimental genotypes tested in this study had $\mathrm{LT}_{50}$ values ranging from -7.0 to $-8.1^{\circ} \mathrm{C}$ and were each lower than that of 'Champion Dwarf'. 'Tahoma 31', the top performing genotype, had an $\mathbf{L T}_{50}$ value ranging from -7.8 to $-9.0^{\circ} \mathrm{C}$ across all three batches. OKC 3920 was the only experimental genotype with an $\mathbf{L T}_{50}$ value in the same statistical group as 'Tahoma 31'. The information gained from this research would be useful for breeders to gauge the genetic gain in freeze tolerance in breeding golf course putting green-type bermudagrass.
\end{abstract}

Bermudagrass (Cynodon spp.) is the most important, widely adapted warm-season turfgrass and is commonly used in golf course putting greens in the transition zone. Many golf courses in this region are converting their putting greens from the cool-season turfgrass, creeping bentgrass (Agrostis stolonifera $\mathrm{L}$.) to interspecific hybrid bermudagrass [C. dactylon (L.) Pers. $\times$ C. transvaalensis Burtt-Davy]. This shift is mainly because managing bermudagrass putting greens can be less expensive than creeping bentgrass because fewer fans for decreasing humidity, fungicides for diseases, and hand-watering for moisture stress are required during summer (Hartwiger,

Received for publication 2 Dec. 2020. Accepted for publication 26 Jan. 2021.

Published online 26 February 2021

Funds to support this research were provided by the Oklahoma Center for the Advancement of Science and Technology (OCAST).

L.G. is the corresponding author. E-mail: lakshmy. gopinath@okstate.edu.

This is an open access article distributed under the CC BY-NC-ND license (https://creativecommons. org/licenses/by-nc-nd/4.0/). mid-1980s (Taliaferro et al., 2004). One of the goals of the breeding program is to develop high-quality bermudagrasses with enhanced freeze tolerance (Taliaferro et al., 2004). The winterhardiness of turfgrasses has been measured in the past using the percentage of winterkill post-spring green-up (Anderson et al., 1988). Such field evaluation methods consume time and sometimes provide inconsistent results due to year-to-year temperature fluctuations and genotype by year interactions. Therefore, artificial freezing tests with a controlled cooling rate have been successfully conducted in the past in a controlled environment to evaluate the freeze tolerance of turfgrasses. Most artificial freezing studies determine the lethal temperatures to kill $50 \%$ of the population $\left(\mathrm{LT}_{50}\right)$ based on the whole-plant regrowth following exposure to freezing temperatures (Anderson et al., 1993, 2002; Dunne et al., 2019; Kimball et al., 2017; Patton and Reicher, 2007; Qian et al., 2001; Shahba et al., 2003). Thus, the objective of this study was to determine the $\mathrm{LT}_{50}$ values of experimental and commercially available putting green hybrid bermudagrass genotypes by subjecting them to 11 freezing temperatures ranging from -4 to $-14{ }^{\circ} \mathrm{C}$, under controlled environment conditions.

\section{Materials and Methods}

The experiment was conducted at the OSU Controlled Environment Research Laboratory at Stillwater, OK. The freezing protocol was performed in accordance with previously conducted studies with slight modifications (Anderson et al., 1993, 2002; Patton and Reicher, 2007). The study was conducted in three batches, due to space constraints in the plant growth chamber and the freeze chamber. Each batch consisted of two standards and two other entries (experimental genotype or commercially available cultivar). The experimental genotypes used in this study were developed by the grass breeding program at OSU. Each batch was replicated in time, with staggered planting to allow uniform establishment periods (Anderson et al., 2007). The first batch consisted of golf course putting green-type interspecific hybrid bermudagrasses OKC6318, 'Tahoma 31', and freeze sensitive and tolerant standard 'Champion Dwarf' (hereafter called 'Champion'), and 'TifEagle', respectively, based on Anderson et al. (2002). 'Tahoma 31' (OKC1131) is a new interspecific hybrid bermudagrass developed by the OSU grass breeding program (Wu et al., 2020). The second batch consisted of OKC0805, OKC1609, 'Tahoma 31', and 'Champion'. The third batch consisted of OKC3920, OKC0920, 'Tahoma 31', and 'Champion'. 'Tahoma 31' and 'Champion' were chosen as the freeze tolerant and sensitive standards, respectively, for the second and third batch, based on the results from the first batch. Bermudagrasses were vegetatively propagated in potting mix (Berger BM 2 propagation mix, Saint-Modeste, QC) in 21-cm deep and 3.8-cm diameter cone-tainers (RayLeach Cone-tainer Nursery, Canby, OR). A single phytomer 
Table 1. Mean lethal temperatures resulting in 50\% survival $\left(\mathrm{LT}_{50}\right)$ of bermudagrass genotypes in the first batch when exposed to temperatures ranging from -4 to $-14{ }^{\circ} \mathrm{C}$ under controlled environment conditions

\begin{tabular}{lc}
\hline Cultivar or genotype & $\mathrm{LT}_{50}\left({ }^{\circ} \mathrm{C}\right)^{\mathrm{y}}$ \\
\hline Champion Dwarf & $-5.9 \mathrm{a}^{\mathrm{x}}$ \\
TifEagle & $-6.3 \mathrm{a}$ \\
OKC6318 & $-7.0 \mathrm{~b}$ \\
Tahoma 31 & $-7.8 \mathrm{c}$ \\
LSD $(0.05)$ & 0.6 \\
\hline z &
\end{tabular}

${ }^{\mathrm{z}}$ The first batch consisted of 'Tahoma 31', OKC6318, freeze susceptible standard 'Champion Dwarf', and freeze tolerant standard 'TifEagle'. The freeze tests were conducted on three dates for this batch, constituting replications in time.

${ }^{\mathrm{y}}$ Lethal temperature to kill $50 \%$ of the population $\left(\mathrm{LT}_{50}\right)$ values were calculated using the PROC PROBIT procedure (SAS version 9.4; SAS Institute, Cary, NC) based on regrowth that was visually evaluated after 5 weeks using binary values; 1 = alive, $0=$ dead.

${ }^{\mathrm{x}}$ Mean separation within column by Fisher's protected least significant difference (LSD) test at $P \leq 0.05$.

Table 2. Mean lethal temperatures resulting in 50\% survival $\left(\mathrm{LT}_{50}\right)$ of bermudagrass genotypes in second batch when exposed to temperatures ranging from -4 to $-14{ }^{\circ} \mathrm{C}$ under controlled environment conditions.

\begin{tabular}{lc}
\hline Cultivar or genotype $^{\mathrm{z}}$ & $\mathrm{LT}_{50}\left({ }^{\circ} \mathrm{C}\right)^{\mathrm{y}}$ \\
\hline Champion Dwarf & $-5.7 \mathrm{a}^{\mathrm{x}}$ \\
OKC0805 & $-7.5 \mathrm{~b}$ \\
OKC1609 & $-7.9 \mathrm{~b}$ \\
Tahoma 31 & $-9.0 \mathrm{c}$ \\
LSD $(0.05)$ & 0.6 \\
\hline
\end{tabular}

${ }^{\mathrm{z}}$ The second batch consisting of standards ' Champion Dwarf' (freeze susceptible) and 'Tahoma 31' (freeze tolerant) and two experimental genotypes, OKC0805 and $\mathrm{OKC} 1609$. The freeze tests were conducted on three dates for this batch, constituting replications in time.

${ }^{\mathrm{y}}$ Lethal temperature to kill $50 \%$ of the population $\left(\mathrm{LT}_{50}\right)$ values were calculated using the PROC PROBIT procedure (SAS version 9.4; SAS Institute, Cary, NC) based on regrowth that was visually evaluated after 5 weeks using binary values; 1 = alive, $0=$ dead.

${ }^{\mathrm{x}}$ Mean separation within column by Fisher's protected least significant difference (LSD) test at $P \leq 0.05$.

consisting of a root, crown, and shoot material was used as the propagation material for each cone-tainer.

Plants were grown in a plant growth chamber (PGC Flex Growth Chamber; Conviron, Winnipeg, Canada) at $32 / 28{ }^{\circ} \mathrm{C}$ day/ night temperatures for 13 weeks, with a photoperiod of $14 \mathrm{~h}(0700$ to $2100 \mathrm{HR})$ and photosynthetically active radiation $(P A R)$ of $900 \mu \mathrm{mol} \cdot \mathrm{m}^{-2} \cdot \mathrm{s}^{-1}$. Plants were fertilized weekly with a general-purpose fertilizer 20N-10P-20K (J.R Peters, Allentown, PA) at $0.6 \mathrm{~g} \cdot \mathrm{L}^{-1}$ and trimmed to maintain a height of $1.3 \mathrm{~cm}$. During the establishment phase, the grasses were treated every $14 \mathrm{~d}$ with bifenthrin insecticide (Talstar; FMC Corp., Philadelphia, PA) rotated with abamectin (Avid 0.15EC; Syngenta, Greensboro, NC) and surfactant (Aduro; Winfield Solutions, LLC, St. Paul, MN) at labeled rates as a precautionary pest-management measure. After 13 weeks of establishment, the temperature was reduced to $24 / 20{ }^{\circ} \mathrm{C}$ for 1 week. Plants were then subjected to cold-acclimation by lowering the temperature to $8 / 2{ }^{\circ} \mathrm{C}$ day/night for 4 weeks, with a photoperiod of $10 \mathrm{~h}(0700$ to $1700 \mathrm{HR}$ ) and a $P A R$ of $400 \mu \mathrm{mol} \cdot \mathrm{m}^{-2} \cdot \mathrm{s}^{-1}$. At the end of 4 weeks of cold acclimation, the plants were transferred to a freeze chamber (E8, plant growth chamber; Conviron, Winnipeg, Canada) maintained at $1{ }^{\circ} \mathrm{C}$. During the final week of acclimation, each cone-tainer was hand-watered to maintain uniform moisture content. Watering was stopped $2 \mathrm{~d}$ before loading samples into the freeze chamber. The cone-tainers were randomized in the freeze chamber within temperature treatments (Patton and Reicher, 2007). Ten thermocouple sensors, logged into the control panel of the freeze chamber, were inserted into random cone-tainers to monitor the soil temperature. Because soil temperatures are more critical than air temperatures when assessing freezing stress (Beard et al., 1991), these thermocouple sensors were inserted $2.5 \mathrm{~cm}$ into the medium at the center of each cone-tainer (Patton and Reicher, 2007). Crushed ice was placed on top of each cone-tainer to prevent supercooling and to initiate ice formation. Then the temperature inside the freeze chamber was gradually reduced to $-3{ }^{\circ} \mathrm{C}$. The chamber temperature was held at $-3{ }^{\circ} \mathrm{C}$ for $18 \mathrm{~h}$ for latent heat to dissipate from the soil. The freeze chamber was then programmed to cool linearly at the rate of 1 ${ }^{\circ} \mathrm{C} \cdot \mathrm{h}^{-1}$. Four cone-tainers of each genotype were removed when the soil temperature reached each target temperature. The target temperatures ranged from -4 to $-14{ }^{\circ} \mathrm{C}$, at $1{ }^{\circ} \mathrm{C}$ intervals, which was the anticipated span from complete survival to complete mortality. The removed cone-tainers were thawed in a plant growth chamber set at $4{ }^{\circ} \mathrm{C}$ for $12 \mathrm{~h}$. Following thawing, the temperature was increased to $24 / 20{ }^{\circ} \mathrm{C}$ for a week and then to $32 /$ $28{ }^{\circ} \mathrm{C}$ to encourage recovery.

The regrowth based on shoot emergence was visually evaluated after 5 weeks using binary values; 1 = alive, $0=$ dead. The $\mathrm{LT}_{50}$ value of each genotype was determined using a logistic regression model using PROC PROBIT (SAS version 9.4; SAS Institute, Cary, NC) (Qian et al., 2001; Shahba et al., 2003). The probit procedure generated a table of predicted percentage survival at each temperature, and the temperature corresponding to $50 \%$ survival was used as the estimate of $\mathrm{LT}_{50}$ for each genotype. Because the freeze test was repeated three times for each batch, there were three $\mathrm{LT}_{50}$ values for each genotype. The $\mathrm{LT}_{50}$ value of each replication was treated as a response variable and was subjected to the analysis of variance (ANOVA) using the SAS procedure PROC ANOVA (Qian et al., 2001). Means were separated using Fisher's protected least significant difference when $F$ tests were significant at $P \leq 0.05$.

\section{Results and Discussion}

The ANOVA results indicated significant differences in the $\mathrm{LT}_{50}$ values among the genotypes in all three batches. The first batch of genotypes (consisting of 'Champion', 'TifEagle', OKC6318, and 'Tahoma 31') ranged in freeze tolerance from -5.9 to $-7.8{ }^{\circ} \mathrm{C}$ (Table 1). 'Champion', the freeze sensitive standard, had the highest $\mathrm{LT}_{50}$ value in this study and was slightly lower than the $\mathrm{LT}_{50}$ value $\left(-4.8^{\circ} \mathrm{C}\right)$ obtained by Anderson et al. (2002), which could be due to the differences in establishment periods. 'TifEagle', the freeze tolerant standard, had an $\mathrm{LT}_{50}$ value like that previously reported by Anderson et al. (2002). Although the $\mathrm{LT}_{50}$ value of 'TifEagle' was numerically lower than 'Champion' in all three runs, it was not different from 'Champion' in this study (Table 1). However, 'Champion' has been reported to be a freeze sensitive cultivar with a significantly higher $\mathrm{LT}_{50}$ value than TifEagle (Anderson et al., 2002). Also, DeBoer et al. (2019) reported that 'Champion' consistently had lower green turf coverage compared with 'TifEagle' for four predicted low-temperature thresholds used for placing putting green covers. The $\mathrm{LT}_{50}$ value of the experimental genotype OKC6318 was like 'TifEagle' but was lower than 'Champion' (Table 1). The similarity coefficient assessed with simple sequence repeat molecular markers by Wang et al. (2010) and Fang et al. (2017) revealed that the existing industry standards used for golf course putting greens such as 'Champion', 'Mini Verde', 'TifEagle', and 'Tifdwarf' formed one group with a genetic similarity coefficient of 1.00 , indicating no genetic diversity among these cultivars. However, the 15 experimental genotypes, including OKC6318, had similarity coefficients ranging from 0.64 to 0.93 , indicating that these experimental genotypes were genetically distinct from the cultivars tested (Fang et al., 2017).

'Tahoma 31' was the top-performing genotype in the first batch with the lowest $\mathrm{LT}_{50}$ value. The superior performance of 'Tahoma 31' was in accordance with field observations. 'Tahoma 31' had the least winterkill rating of $14.5 \%$ when averaged across two trial locations (Indiana and Kentucky) and exhibited superior post-dormancy regrowth in the field (NTEP, 2014). 'Tahoma 31 ' has also shown quick postdormancy regrowth after exposure to prolonged chilling stress $\left[8 / 2{ }^{\circ} \mathrm{C}\right.$ (day/night)] under a controlled environment, indicating its superior recovery potential when subjected to low temperatures (Fontanier et al., 2020).

Due to the lower $\mathrm{LT}_{50}$ value of 'Tahoma 31' compared with 'TifEagle', the former was used as the freeze tolerant standard for subsequent batches. The $\mathrm{LT}_{50}$ values of the second batch (consisting of 'Champion', 'Tahoma 31', OKC0805, and OKC1609) ranged from -5.7 to $-9.0^{\circ} \mathrm{C}$ (Table 2). Like the first batch, 'Champion' and 'Tahoma 31' had the highest and lowest $\mathrm{LT}_{50}$ values, respectively, and these were significantly different from the other genotypes tested in the second batch. The experimental genotypes OKC0805 and OKC1609 had improved freeze tolerance compared with 'Champion' but poorer freeze tolerance than 'Tahoma 31'.

The $\mathrm{LT}_{50}$ values of the third batch (consisting of 'Champion', 'Tahoma 31', OKC0920, 
Table 3. Mean lethal temperatures resulting in 50\% survival $\left(\mathrm{LT}_{50}\right)$ of bermudagrass genotypes in the third batch when exposed to temperatures ranging from -4 to $-14{ }^{\circ} \mathrm{C}$ under controlled environment conditions.

\begin{tabular}{lc}
\hline Cultivar or genotype $^{\mathrm{z}}$ & $\mathrm{LT}_{50}\left({ }^{\circ} \mathrm{C}\right)^{\mathrm{y}}$ \\
\hline Champion Dwarf & $-5.2 \mathrm{a}^{\mathrm{x}}$ \\
OKC0920 & $-7.1 \mathrm{~b}$ \\
OKC3920 & $-8.1 \mathrm{c}$ \\
Tahoma 31 & $-8.8 \mathrm{c}$ \\
LSD $(0.05)$ & 0.8 \\
\hline
\end{tabular}

${ }^{\mathrm{z}}$ The third batch consisting of standards 'Champion Dwarf' (freeze susceptible) and 'Tahoma 31' (freeze tolerant) and two experimental genotypes, OKC0920 and OKC3920. The freeze tests were conducted on three dates for this batch, constituting replications in time.

${ }^{\mathrm{y}}$ Lethal temperature to kill $50 \%$ of the population $\left(\mathrm{LT}_{50}\right)$ values were calculated using the PROC PROBIT procedure (SAS version 9.4; SAS Institute, Cary, NC) based on regrowth that was visually evaluated after 5 weeks using binary values; $1=$ alive, $0=$ dead .

${ }^{\mathrm{x}}$ Mean separation within column by Fisher's protected least significant difference (LSD) test at $P \leq 0.05$.

and $\mathrm{OKC} 3920$ ) ranged from -5.2 to $-8.8{ }^{\circ} \mathrm{C}$ (Table 3). The standards exhibited a similar trend, with 'Champion' and 'Tahoma 31' being the worst and top-performing genotypes, respectively. The experimental genotype OKC0920 was significantly different from other genotypes in this batch. The genotype OKC3920 was the only experimental genotype test with a similar freeze tolerance to 'Tahoma 31' in this study.

The commonly used ultradwarf bermudagrass cultivars, if not all, are mutations from 'Tifgreen' bermudagrass (Harris-Shultz et al., 2010). The narrow genetic diversity of these ultradwarf bermudagrasses could make them susceptible to new or existing disease or insect pests, leading to extensive damage (Taliaferro, 1995). The release of these experimental genotypes, which are genetically distinct, could substantially increase the genetic diversity of greens-type bermudagrass cultivars and could increase their resistance to prevalent pests and diseases. These winter-hardy bermudagrass genotypes could also help expand the geographical area where it could be grown successfully. Ultradwarf bermudagrasses are the preferred choice for golf course putting greens due to their ability to produce high-quality turf with faster ball rolls at a low cutting height of $3.2 \mathrm{~mm}$ compared with older ultradwarf cultivars (Beard and Sifers, 1996). The authors have observed that 'Tahoma 31', the topperforming genotype in this study, could tolerate a mowing height of $3.8 \mathrm{~mm}$ and above, and that it could produce a satisfactory golf course putting green surface. Using these freeze tolerant bermudagrasses could reduce the current USGA-recommended threshold air temperature of $-4{ }^{\circ} \mathrm{C}$ (O'Brien and Hartwiger, 2013) for covering the golf course putting greens. Lowering the threshold temperature without an increase in winter injury can result in fewer covering events, thus minimizing the labor cost involved. Also, golf courses with winter-hardy bermudagrass greens benefit fi- nancially by keeping the facility open for play for more days in the winter.

There have been instances when rankings from field studies do not entirely match laboratory studies because of the thermal buffering capacity of the soils as meristems in the field are protected from cold air temperatures (Anderson et al., 2002). Controlled environment studies will be a useful tool for breeders to rapidly screen genotypes for freeze tolerance. However, to increase the efficacy of selection and understand the genotype $\times$ environment interaction multi-year, multi-location evaluations are needed. The experimental genotypes OKC3920, OKC0805, and OKC0920 have been entered into the 2019 to 2024 National Turfgrass Evaluation Program warm-season putting green trial for multi-year and multi-location field testing. This testing will provide an opportunity to expose these new experimental genotypes to diverse environmental conditions for examining their performance and adaptation in the United States.

A total of five experimental genotypes were tested in this research. Each of these experimental genotypes had $\mathrm{LT}_{50}$ values lower than 'Champion'. 'Tahoma 31', an improved cultivar adapted to shorter mowing heights, was the top-performing genotype with a mean $\mathrm{LT}_{50}$ value of $-7.8^{\circ} \mathrm{C}$ in all three batches. This study was the first to test 'Tahoma 31' for freeze tolerance under controlled environment conditions. 'Tahoma 31' could be used as a freeze tolerant standard for future bermudagrass freeze tolerance studies due to its superior performance in the field and controlled environment evaluations. The experimental genotype OKC3920 was the only experimental genotype with a similar freeze tolerance to 'Tahoma 31'. The OSU experimental genotypes tested in this study could be pursued for possible commercial release if found to have a promising and consistent turf quality, disease resistance, and low mowing tolerance.

\section{Literature Cited}

Anderson, J.A., M.P. Kenna, and C.M. Taliaferro. 1988. Cold hardiness of 'Midiron' and 'Tifgreen' bermudagrass. HortScience 23:748-750.

Anderson, J.A., C.M. Taliaferro, and D.L. Martin. 1993. Evaluating freeze tolerance of bermudagrass in a controlled environment. HortScience 28:955-959, doi: 10.21273/HORTSCI.28.9.955.

Anderson, J.A., C.M. Taliaferro, and D.L. Martin. 2002. Freeze tolerance of bermudagrasses: Vegetatively propagated cultivars intended for fairway and putting green use, and seedpropagated cultivars. Crop Sci. 42:975-977, doi: $10.2135 /$ cropsci2002.9750.

Anderson, J.A., C.M. Taliaferro, D.L. Martin, Y.Q. Wu, and M. Anderson. 2007. Freeze tolerance of seedand vegetatively-propagated bermudagrasses compared with standard cultivars. Appl. Turfgrass Sci. 4:1-7, doi: 10.1094/ATS-2007-0508-01-RS.

Beard, J.B., S.I. Sifers, and S.D. Griggs. 1991. Genetic diversity in low temperature hardiness among 35 major warm-season turfgrass genotypes. Texas Turfgrass Research: 1989-1990 4898:56-58.

Beard, J.B. and S.I. Sifers. 1996. New cultivars for southern putting greens. Golf Course Manage. 64:58-62.

DeBoer, E.J., M.D. Richardson, J.H. McCalla, and D.E. Karcher. 2019. Reducing ultradwarf bermu- dagrass putting green winter injury with covers and wetting agents. Crop. Forage and Turfgrass Manage. 5:1-9, doi: 10.2134/cftm2019.03.0019.

Dunne, J.C., T.D. Tuong, D.P. Livingston, W.C. Reynolds, and S.R. Milla-Lewis. 2019. Field and laboratory evaluation of bermudagrass germplasm for cold hardiness and freezing tolerance. Crop Sci. 59(1):392-399.

Fang, T., Y.Q. Wu, J.Q. Moss, N.R. Walker, and D.L. Martin. 2017. Genetic diversity of greens-type bermudagrass genotypes as assessed with simple sequence repeat markers. Intl. Turfgrass Soc. Res. J. 13:1-8, doi: 10.2134/itsrj2016.05.0435.

Fontanier, C., J.Q. Moss, L. Gopinath, C. Goad, K. $\mathrm{Su}$, and Y.Q. Wu. 2020. Lipid composition of three bermudagrasses in response to chilling stress. J. Amer. Soc. Hort. Sci. 145:95-103, doi: 10.21273/JASHS04815-19.

Harris-Shultz, K.R., B.M. Schwartz, W.W. Hanna, and J.A. Brady. 2010. Development, linkage mapping and utilization of microsatellites in bermudagrass. J. Amer. Soc. Hort. Sci. 135:511-520, doi: 10.21273/ JASHS.135.6.511.

Hartwiger, C. 2009. The heat is on: The first decade of the 21 st century has seen ultradwarf bermudagrass varieties replacing bentgrass on putting greens in the Southeast. USGA Green Sect. Rec. 47(2):1-7.

Juska, F.V. and A.A. Hanson. 1964. Evaluation of bermudagrass varieties for general-purpose turf. Agricultural Handbook No. 270. ARS/ USDA, Washington, DC.

Kimball, J.A., T.D. Tuong, C. Arellano, D.P. Livingston, and S.R. Milla-Lewis. 2017. Assessing freeze-tolerance in St. Augustinegrass: Temperature response and evaluation. Euphytica 213:(110), doi: 10.1007/s10681-0171899-z.

NTEP. 2014. Progress report NTEP no. 15-2. 2013 National bermudagrass test. 4 June 2020. <http:// ntep.org/reports/bg13/bg13_15-2/bg13_15-2.htm>.

O'Brien, P. and C. Hartwiger. 2013. Covering guidelines for ultradwarf bermudagrass putting greens. United States Golf Association 9:1-2.

Patton, A.J. and Z.J. Reicher. 2007. Zoysiagrass species and genotypes differ in their winter injury and freeze tolerance. Crop Sci. 47:1619 1627, doi: 10.2135/cropsci2006.11.0737.

Qian, Y.L., S. Ball, Z. Tan, A.J. Koski, and S.J. Wilhelm. 2001. Freeze tolerance of six cultivars of buffalograss. Crop Sci. 41:1174-1178, doi: $10.2135 /$ cropsci2001.4141174x.

Shahba, M.A., Y.L. Qian, H.G. Hughes, A.J. Koski, and D. Christensen. 2003. Relationships of soluble carbohydrates and freeze tolerance in saltgrass. Crop Sci. 43:2148-2153, doi: 10.2135/ cropsci2003.2148.

Taliaferro, C.M. 1995. Diversity and vulnerability of bermuda turfgrass species. Crop Sci. 35:327-332, doi: 10.2135/cropsci1995.0011183X0035000 $20006 \mathrm{x}$

Taliaferro, C.M., D.L. Martin, J.A. Anderson, M.P. Anderson, and A.C. Guenzi. 2004. Broadening the horizons of turf bermudagrass. U.S. Golf Assoc. Turf. Environ. Res. Online. 3(20):1-9. $<$ https://usgatero.msu.edu/v03/n20.pdf $>$.

Wang, Z., Y. Wu, D.L. Martin, H. Gao, T. Samuels, and C. Tan. 2010. Identification of vegetatively propagated turf bermudagrass cultivars using simple sequence repeat markers. Crop Sci. 50:21032111, doi: 10.2135 /cropsci2010.02.0116.

White, B. 2011. Moving north with ultradwarf bermudagrass greens. Bul. Sports Surface Manage. 255:35-37.

Wu, Y., D.L. Martin, J.Q. Moss, N.R. Walker, and C. Fontanier. 2020. Bermudagrass plant named 'OKC 1131'. US patent PP31695. 20 Jan. 2021. <https:// www.freepatentsonline.com/PP31695.html $>$. 